\title{
The size-weight illusion in 2-D nonlinear psychophysics
}

\author{
ROBERT A. M. GREGSON and L. ANNA BRITTON \\ University of New England, Armidale, New South Wales, Australia
}

\begin{abstract}
An extension of unidimensional nonlinear psychophysics is postulated by using forms of crosscoupling between the parameters of the two single-channel recursions, which have already been shown to model some perceptual phenomena. The size-weight illusion is shown to be reproducible in the topology of its relations, and it is suggested that some so-called illusions are in fact the natural consequences of nonlinear cross-coupling. The conditions that produce the illusion involve partially compensating the cross-coupling of sensory dimensions, and a second equilibrium with no cross-coupling, resembling simpler veridical perception, also exists in the behavior of some subjects.
\end{abstract}

The emergence of a rapidly growing body of results on nonlinear systems, first in the physical sciences and now on a much wider area of potential application, has produced an extensive literature. Some of this is popularization for the nonmathematician (Gleick, 1987; Prigogine \& Stengers, 1984), and the rigorous part is either mathematics (Gumowski \& Mira, 1980; Kreuzer, 1987; Wiggins, 1988) or applications and discussions of metatheoretical problems (Caianiello, 1987; Feder, 1988; Livi, Ruffo, Ciliberto, \& Buiatti, 1988; Schuster, 1984). The use of nonlinear models in brain processes appears often under the rubric of synergetics, for which a series of volumes has emerged (Başar, Flohr, Haken, \& Mandell, 1983). By 1984, over 400 papers on chaotic systems had appeared (Hao, 1984), and probably another 200 have appeared since, but only very few with any quantitative content have surfaced in psychology. As might be expected, disputes arise as to whether all this represents a paradigm shift in the Kuhnian sense, or is an extension of what at least the specialists in dynamic theory knew already. The roots of the mathematical analysis are found in the earlier work of such French mathematicians as Poincaré and such Soviet mathematicians as Andronov. Psychologists have apparently been largely unaware of the implications of this activity for their own discipline. The predominant importance of nonlinear dynamics for psychophysical theory lies in the breakdown of the idea that changes in responses within the organism are directly proportional to changes in the level of external stimulation. In other words, as a generalization, the basic assumptions of Fechnerian psychophysics are taken as being a priori false, except in that they may be locally, and only locally, useful. If may therefore be of wider interest to

This paper was prepared originally for the Australian 15th Annual Experimental Psychology Meeting in July 1989. Part of the work was supported by Grant A78831403 from the Australian Research Council to R. A. M. Gregson. Correspondence should be addressed to R. A. M. Gregson, Department of Psychology, University of New England, Armidale, N.S.W., Australia. illustrate some of the problems inherent in working within a framework that is certainly atypical at present. This is best done by considering a specific model.

This study is concerned with the application of a general nonlinear model, $2 \Gamma$, of interdimensional interaction in sensation to the specific case of the size-weight illusion, which is a classic problem in experimental psychology. The theory was not derived in order to predict any of the detailed psychophysical relationships found within sizeweight interaction data, and so the application has the status of showing that if the completely general abstract model fits in some details, then the size-weight illusion is one of a family of related phenomena generated by a common central process that produces analogous instances in the same and in other sensory modalities.

The original model, which is used here as our starting point, was developed to give a coherent framework within which a diversity of phenomena associated with the perception of the intensity of a unidimensional sensory input could be accommodated. The reasons for doing this are various (19 reasons are given by Gregson, 1988), but briefly, it was desired to set up a recursive process, of minimal complexity, from which could be derived something like the cumulative normal ogive which approximates many psychophysical input-output plots. This approach was then extended to other phenomena, including the subjective Weber function, and signal detection. In doing this, only processes for which there exist evidence of their generation at the neural substrate level can be postulated. It is known that sensory pathways at higher cortical levels can be multiple, recursive, perseverative, and nonlinear. There are also grounds for treating large aggregates of connected neural structures as capable of generating nonlinear and chaotic dynamics as part of their normal functioning. Given these constraints, a cubic complex polynomial recursion $\Gamma$ was defined, which satisfies the criteria stipulated. This model generates, intrinsically, both observable response and unobservable (theoretical, deterministic) noise at the same time, without excluding 
the fact that additional stochastic noise can also exist in the system modeled. It is a property of such a model that it shows phase changes, and in some regions of its parameter space (that is, the multidimensional mathematical space defined and spanned by the range of the values that its parameters can take) the process is one $\rightarrow$ one : stimulus $\rightarrow$ response, in other regions it is one $\rightarrow$ many, and under overload it can become chaotic, and degenerate. The necessity of one $\rightarrow$ many modeling in psychology has been noted also, from a different perspective, by Smithson (1988) in criticizing the use of the general linear model in Neyman-Pearson inference in psychological statistics.

Using a model of this sort, in strong contradistinction to the familiar psychophysical equations commonly associated with the names of Fechner or S. S. Stevens, there is no need to add constants to the psychophysical equations to represent upper and lower threshold regions; the phase changes represent diverse functioning at extreme values of the inputs.

It may be noted that this model, in the form in which it is used here, says nothing about response latencies or about decision processes between competing inputs. In the unidimensional form given by Price and Gregson (1988) and by Gregson (1988), no testable development of the model to handle multidimensional inputs and outputs was given, although the problem was foreshadowed. Some of the fundamental mathematics of the nonlinear dynamics have recently been extended in order to examine the Julia sets of the $\Gamma$ recursion; in this context, those sets effectively define the system boundaries within which dynamical stability should occur, and are therefore of both mathematical and psychological interest.

In this latter context, Campbell and Gregson (in press) use the property that a recursion in complex form can instead be written, mainly for computational convenience and without substantive reinterpretation, as two simultaneous cross-linked recursions in real variables. The complex variable $\Gamma$ form discussed in detail (Gregson, 1988) can be interpreted as the equation of a feedforward loop which runs for a few iterations and converges (in and only in some regions of the parameter space), and thus has a potential neurophysiological interpretation. In the second form, with two real equations, it can also be interpreted as two coupled oscillators, and thus has in mathematical terms a familial resemblance to the type of dynamics studied since van der Pol in physics. We do not use this form here, as in fact it is less simple, but mention it for completeness, since a referee expressed interest. What are called phase-space portraits of the system's dynamics have been given in various forms in the previous studies using $\Gamma$ and $2 \Gamma$ modeling.

\section{THE UNIDIMENSIONAL FORM OF A RECURSIVE CHANNEL}

In the model $\Gamma$, a representation of a unidimensional sensory channel in psychophysics is, with $a$ as input value and $Y$ as output, a recursive feedforward loop process, in discrete steps, $j$, having as defining equation.

$$
\begin{array}{r}
Y_{j+1}=-a\left(Y_{j}-1\right)\left(Y_{j}-i e\right)\left(Y_{j}+i e\right) \quad i=\sqrt{-1}, \\
\text { (Gregson, 1988, Equation 2.2) }
\end{array}
$$

where $a$ is $\operatorname{Re}$, $i e$ is $\operatorname{Im}$, so that $Y$ is complex $(\operatorname{Re}, \operatorname{Im})$, it is found that this recursion exhibits very complicated dynamics with interplay of the effects of $a$ and $e$. The boundary conditions are $0<Y(\operatorname{Re})<1$, and for simulations here, unless otherwise stated, $Y_{0}=(\zeta, \epsilon), \zeta \leq .5$, $\epsilon<10^{-8}, 2<a<5,0<e<.5$, and very approximately $a e<1.7$, in the region of $.5<e<.7$.

In this $\Gamma$ model, which has to be extended to two dimensions here, the original form for a unidimensional sensory channel has the following parameters: $U_{h}$ is the physical input on dimension $h ; U_{h}$ operates directly on the gain parameter $a_{h}$ of the recursive feedforward loop, but not on $Y$, which is an autonomous internal-state variable; the loop runs for $\eta$ recursions on the internal variable $Y$ and then jumps out; and hence the observed output, as response is $Y(\mathrm{Re})$ after $\eta$ recursions. This value is denoted by $Y_{\text {obs }}$ in previous studies cited here. Analytic treatments of the details of the nonlinear mathematics of this recursion are given by Gregson (1988, 1989a), Price and Gregson (1988), and Campbell and Gregson (in press). Note that the notation here is consistent with these previous sources; in mathematical texts, it is usual to write $\mathfrak{A}, \mathfrak{I}$ for the real and imaginary parts of the complex variable $Y$.

\section{ADDING WITHIN THE LOOP}

It is necessary to make some strong simple assumptions about how a double, or multiple, loop could work. Mathematically it is an unexplored problem, and given the nonlinearity of the recursion, some paradoxical behavior is to be expected for some parameter values.

Going to two dimensions, some theory-construction problems face the investigator, because parameter proliferation should be avoided. It turns out that one can actually reduce the number of parameters to be estimated when one goes from one to two dimensions, and use only three $\left(a_{1}, a_{2}, \lambda\right)$ instead of four $\left(a_{1}, e_{1}, a_{2}, e_{2}\right)$. This is shown below in the system equations. We note, parenthetically, that we can drop another parameter, $\eta$, by using, instead of a constant arbitrary stopping rule for the recursion, a property of the Jacobian of the $\Gamma$ recursion written in two reals (Gregson, 1989c), which, with restricted values of $(a, e)$, converges onto an attractor at a rate inversely proportional to the level of stimulus input. As this is an additional reason for using the model (not included in the 19 reasons given previously), it is mentioned for completeness, although is not needed here.

The cross-coupled form $2 \Gamma$ has been used already in exploring two cases where there are two independent inputs, but only one response which corresponds to perceived total aqualitative intensity. These are Fechner's paradox (Gregson, 1989b) and hypoaddition in odor mixtures (Gregson, 1989a; Gregson \& Britton, 1989). The 
present case uses exactly the same core model as in these two previous examples, but considers instead two separate qualitative responses; there is no defined analogue of total intensity elicited as a response here. This does not mean that there could not be any such observation or prediction; it means that the relevant extensive empirical literature does not consider the point explicitly.

\section{INTRAMODALITY INTERACTION}

The structure of $2 \Gamma$ is intended to represent intersensory interactions. Within one channel, activity is only $Y(\operatorname{Re}, \mathrm{Im})$; to represent fully vision or audition requires a vector $Y$ instead of $Y$. We consider two cases, which differ in their cross-coupling between channels; the first is simpler and would not generate the anomalies which might characterize the size-weight illusion.

1. If the Im output of $Y_{\text {obs }}$ (which is the value of $Y$ after $\eta$ recursions) is taken as interpretable as a form of internal noise, as has been shown to be plausible in other contexts, then let us take the total within-loop noise level at any step in the recursion to be the union of the component noises. So, in each cycle, the two $Y(\mathrm{Im})$ are replaced by the term $\max \left(Y_{1}, j, Y_{2}, j\right)(\mathrm{Im})$, and as the Im components go into limit cycling more readily (that is, at lower system parameter values) than their Re counterparts, the effect will depend crucially on the set of values $\left(a_{1}, e_{1}, a_{2}, e_{2}\right)$. It can be shown, by simulation, that high $\left(e_{1}, e_{2}\right)$ values induce some curious effects for large $U_{J}$ (inputs); a paradoxical "turnover" effect in $U \vdash Y_{\text {obs }}$ graphs for at least one component is observable. At the same time the other component may create a monotonically decreasing graph of $U \mapsto Y_{\text {obs }}$.

2. A second cross-linkage is possible if the $e$ terms are made to be functions of the $a$ terms in the opposite dimension. This represents a process of mutual inhibition. Each dimension is desensitized to differences in its own input as the input to the other dimension is increased, viz:

$$
e_{1}=\lambda_{1} \cdot a_{2}^{-1}, \quad e_{2}=\lambda_{2} \cdot a_{1}^{-1},
$$

where $\lambda_{1}>0, \lambda_{2}>0$, and $2.6<a_{\min }<4.4$ is a working range for $0.05<e<0.40$, and approximately $.20<\lambda<1.2$ will avoid the explosive condition (Gregson, 1988, chap. 2) of $a e>1.7$.

The advantage of writing Equations 1,2 is that the number of parameters in the model is reduced by one, $e_{1}$ and $e_{2}$ are removed, and $\lambda$ is introduced, with $\lambda_{1}=\lambda_{2}=\lambda$. For a double loop, put, for case 1 , where the two dimensions are denoted by $h$ and $i$ suffixes,

$$
Y_{h i j}(\mathrm{Im})=\max \left[Y_{h j}(\mathrm{Im}), Y_{i j}(\mathrm{Im})\right]
$$

and then define

$$
Y_{h j}^{*}=\left[Y_{h j}(\mathrm{Re}), Y_{h i j}(\mathrm{Im})\right]
$$

and

$$
Y_{i j}^{*}=\left[Y_{i j}(\mathrm{Re}), Y_{h i j}(\operatorname{Im})\right]
$$

For case 2, we have instead

$$
Y_{h(j+1)}=-a_{h} \cdot\left[Y_{h j}^{*}-1\right]\left[Y_{h j}^{*}-i \lambda_{h} \cdot\left(a_{i}\right)^{-1}\right]\left[Y_{h j}^{*}+i \lambda_{h} \cdot\left(a_{i}\right)^{-1}\right]
$$

and correspondingly

$$
Y_{i(j+1)}=-a_{i} \cdot\left[Y_{i j}^{*}-1\right]\left[Y_{i j}^{*}-i \lambda_{i} \cdot\left(a_{h}\right)^{-1}\right]\left[Y_{i j}^{*}+i \lambda_{i} \cdot\left(a_{h}\right)^{-1}\right] \text {. }
$$

The behavior of case 2 as a simulation of phenomena associated with Fechner's paradox has been examined in some detail previously (Gregson, 1989b). Figure 1 shows diagrammatically the linkages in case 2 . The boxes labeled $\Gamma_{1}$ and $\Gamma_{2}$ are a representation of the two recursive loops, not simple linear pathways.

\section{THE SIZE-WEIGHT ILLUSION}

To assess the plausibility of effects such as those predicted in case 2 , it is helpful to consider sensory phenomena in which at least two sensory inputs, peripherally unconnected, are coalesced in some way in determining responses to each of the stimulus dimensions separately. Sensory interaction phenomena have been studied in various contexts, involving such variables as velocity, brightness, and loudness (Ottander, 1967). The target for study here is the size-weight illusion (Anderson, 1970, 1982; Bredenkamp, 1984; Brunswik, 1933; Charpentier, 1891; Claparède, 1902; Cross \& Rotkin, 1975; Flournoy, 1894; Friedländer, 1920; Fries \& Holmberg, 1967; Huang, 1945a, 1945b; Jones, 1986; Kolehmainer \& Mikkonen, 1970; Koseleff, 1936, 1957; Masin \& Crestoni, 1988; Nyssen \& Bourdon, 1955; Ross, 1966; Ross \& Gregory, 1970; J. C. Stevens \& Rubin, 1970; Thouless, 1931a, 1931b; Usnadze, 1931).

Since Charpentier was one of the earliest workers to report on the illusion, it was sometimes named after him. It can be shown, under conditions of the simultaneous seeing and lifting of an object, that the apparent weight of the object (relative to its physical weight) decreases as its physical size increases, on average. The underlying

Scheme of Two Nonlinear Recursive Loops in Parallel

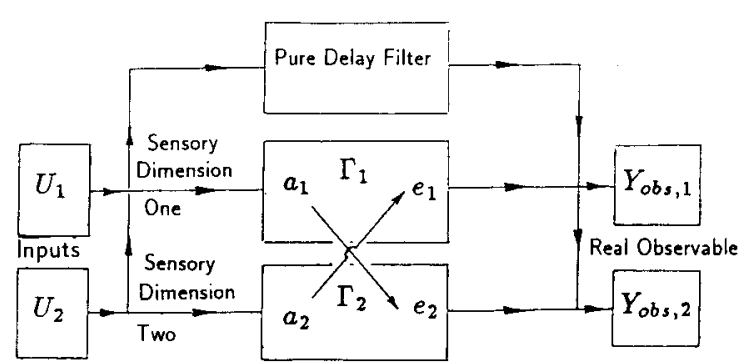

Figure 1. Scheme of two nonlinear recursive loops in parallel. Case 1 has no cross-coupling between channels; case 2 is as shown with the crossing lines between boxes $\Gamma_{1}$ and $\Gamma_{2}$. 


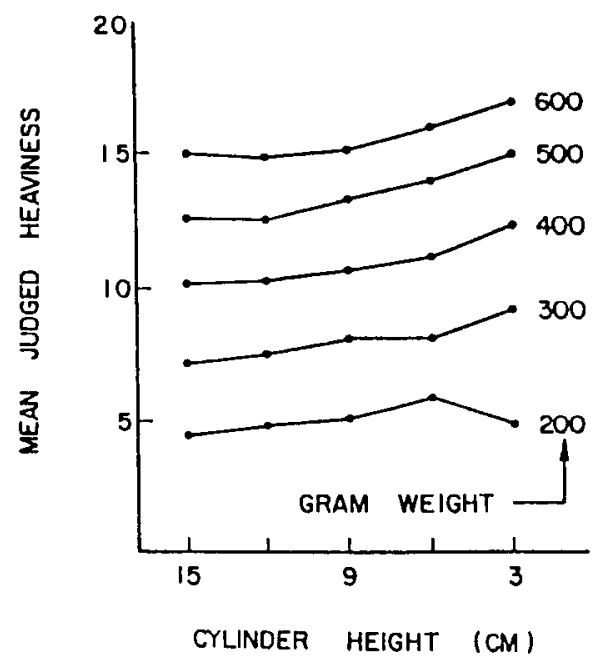

Figure 2. Results from Anderson (1982) showing judgments of felt heaviness for a series of cylinders varying in height and weight. Reprinted by permission. mechanism is not simply due to muscle actions, as it can persist under partial anesthesia (Ross, 1966), though a great variety of procedures for lifting weights have been used since the 1890 s. The effect is usually small and consistent, when it occurs, and a diversity of mathematical models have been fitted to the effect (Rule \& Curtis, 1976; Sjöberg, 1969). Most of these models are post hoc curvefitting equations, and in no sense derivations from a more general process model of sensory interaction. By inspection of published graphs, it can be seen that linear models, or derivations from them, fail to fit data over at least a subset of the conditions explored. One clear example, from Anderson (1982), is shown in Figure 2 for illustration.

Major sources we have been able to cite are listed in Table 1; we have abstracted, from left to right, the number of subjects used, the weight range of the stimuli presented, the length or volume range, the time (or calculated mean time) interval between elicited judgments, the number of different weights used in the stimulus series, the number of different sizes, and lastly (if it could be deduced from published graphs or tables), the presence

Table 1

Previous Experiments

\begin{tabular}{|c|c|c|c|c|c|c|c|c|}
\hline Author(s) & Date & $\begin{array}{c}\text { Number of } \\
\text { Subjects }\end{array}$ & $\begin{array}{c}\text { Weight Range } \\
\text { (grams) }\end{array}$ & $\begin{array}{c}\text { Length or } \\
\text { Volume Range }\end{array}$ & $\begin{array}{c}\text { Time } \\
\text { Interval* }\end{array}$ & $\begin{array}{c}\text { Number of } \\
\text { Weights }\end{array}$ & $\begin{array}{c}\text { Number of } \\
\text { Sizes }\end{array}$ & $\begin{array}{c}\text { Nonlinearity } \\
\text { Evidence }\end{array}$ \\
\hline Flournoy & 1894 & 49 & 112 & $10,2100 \mathrm{cc}$ & - & 1 & 10 & - \\
\hline Bolton & 1898 & 25 & 35,65 & $3,9 \mathrm{~cm}$ & - & 4 & 3 & no \\
\hline Wolfe & 1898 & 40 & 15,525 & $7000 \mathrm{cc}$ & - & 31 & 31 & - \\
\hline Loomis & 1907 & 36 & 352 & $(3.7,22.7 \mathrm{~cm})^{3}$ & - & 1 & 2 & - \\
\hline Fischel & 1926 & 6 & 500,1000 & $(12 \mathrm{~cm})^{3}$ & - & 2 & 1 & no \\
\hline Fischel & 1926 & 6 & 500,1250 & $(12 \mathrm{~cm})^{3}$ & - & 4 & 1 & no \\
\hline Usnadze & 1931 & 28 & 286,880 & $1.5,10 \mathrm{~cm}$ & - & 2 & 8 & - \\
\hline Oberlin & 1936 & - & 92,108 & - & - & 5 & 1 & yes \\
\hline Oberlin & 1936 & - & 92,108 & - & - & 25 & - & yes \\
\hline Huang & $1945 b$ & 40 & 240 & $4,8 \mathrm{~cm}$ & 6 & 1 & 5 & - \\
\hline Harper and S. S. Stevens & 1948 & 12 & 12,1850 & $0.8,9.9 \mathrm{~cm}$ & - & 56 & 4 & - \\
\hline Furth & 1960 & 20 & 152,248 & $5.8,8.25 \mathrm{~cm}$ & - & 5 & 6 & yes \\
\hline Robinson & 1964 & 144 & 15,125 & $3.3,5.4 \mathrm{~cm}$ & - & 6 & 5 & yes \\
\hline Freeman and Adam & 1965 & 20 & 200,400 & $17.8 \mathrm{~cm}$ & - & 5 & 1 & yes \\
\hline Ross & 1966 & 9 & 80,220 & $962.7,38.6 \mathrm{cc}$ & - & 10 & 2 & - \\
\hline Gregory and Ross & 1967 & 1 & 103,120 & $4.8 \mathrm{~cm}$ & $\cong 30$ & 1 & 1 & - \\
\hline Oostlander & 1967 & 84 & 102,390 & $6.4,24.4 \mathrm{~cm}$ & - & 7 & 7 & - \\
\hline Anderson and Jacobson & 1968 & 84 & 50,140 & - & 20 & 10 & - & no \\
\hline Anderson and Jacobson & 1968 & 84 & 50,140 & - & 22 & 10 & - & no \\
\hline Ross & 1969 & 15 & 90,165 & $550,4005 \mathrm{cc}$ & - & 17 & 4 & - \\
\hline Ross & 1969 & 15 & 60,180 & $18.5,326.9 \mathrm{cc}$ & - & 62 & 4 & - \\
\hline Ross & 1969 & 15 & 160,270 & $38.6,962.7 \mathrm{cc}$ & - & 15 & 4 & yes \\
\hline Anderson & 1970 & 24 & 150,250 & $4,7.2 \mathrm{~cm}$ & 7 & 3 & 5 & yes \\
\hline Harshfield and DeHart & 1970 & 90 & 142 & $3.8 \mathrm{~cm}$ & - & 1 & 1 & - \\
\hline J. C. Stevens and Rubin & 1970 & 14 & 25,6400 & $58,2325 \mathrm{cc}$ & - & 9 & 1 & yes \\
\hline Anderson & 1972 & 20 & 200,600 & $3.3,15.3 \mathrm{~cm}$ & - & 5 & 5 & yes \\
\hline Davis & 1973 & 18 & - & $6.4,9 \mathrm{~cm}$ & 40 & 1 & 2 & - \\
\hline Birnbaum and Veit & 1974 & 16 & 50,400 & $5.5,8.7 \mathrm{~cm}$ & $\cong 4.25$ & 7 & 3 & yes \\
\hline Cross and Rotkin & 1975 & 20 & 51,6168 & $94,4710 \mathrm{cc}$ & $\cong 28.4$ & 9 & 9 & yes \\
\hline Davis and Brickett & 1977 & 12 & 500 & $236,946 \mathrm{cc}$ & 30 & 12 & 2 & - \\
\hline Davis, Taylor, and Brickett & 1977 & 13 & 500 & $946 \mathrm{cc}$ & 30 & 1 & 1 & - \\
\hline Masin and Crestoni & 1988 & 120 & 150,765 & $4.5,9 \mathrm{~cm}$ & - & 5 & 3 & yes \\
\hline
\end{tabular}


of evidence of nonlinearities of the sort generated in the $2 \Gamma$ model. The great diversity of methods used is not fully illustrated by this skeletal tabulation.

As closer review of the lengthy literature shows that the size-weight effect appears to be modifiable by the cognitive set (Einstellung) of the observer, and is an average effect over a spread of judgments that can go in either direction (a physical size increment induces either a shift toward heavier or toward lighter judged weight), the process should be thought of as apparently stochastic. We say apparently stochastic because there may be a chaotic phase in the process and one or more distinct system equilibria; none of the published work considers this possibility, as is done here.

A further complication arises because it is not clear exactly what the stimulus dimensions are, and it is, to say the least, expedient to know what physical properties to map onto $U_{i}$ in the $2 \Gamma$ model. The stimulus variables of an object that has mass and spatial extension are weight, density, and volume (the latter confounded with shape parameters) and, as shown by Koseleff (1936), the distribution of mass within the object. According to Huang (1945a), density may in fact refer to two sensory effects, which had separate designating words in some Chinese dialects. This complication has not escaped other investigators, who used very specific instructions to try to remove any confounding of judgments of density and of weight in their subjects' responses. Methods of data analysis used took no account of sequential effects between trials, either in terms of immediate autoregression or longterm drift (admittedly some early investigators specifically mentioned the existence of such sequential effects), although the lability of the interaction between dimensions suggests strongly that both will be present.

\section{THE COMPLEMENTARY SIZE - WEIGHT AND WEIGHT-SIZE EXPERIMENTS}

For completeness in the present analysis, one should also have data on apparent size as real weight is altered. This was done by Usnadze (1931), who gave sparse quantitative results, and indicated that the weight-size illusion did not exist (physical weight does not affect perceived size) if vision is available. ${ }^{1}$ However, the extent of the asymmetry of the illusion is secondary as compared with the prediction of its existence. It is reported in the cited studies that the illusion is small, associated with only light weights, strongest in children, and stronger in women than in men (Wolfe, 1898), and that apparent weight can also be modified by the surface material, color, and density of the objects being lifted (for a review, see Jones, 1986). In $2 \Gamma$, the substitutions

$$
\begin{array}{ll}
U_{1} & =\text { weight in grams, } U_{2}=\text { size in centimeters, } \\
Y_{1} & =\text { heaviness, } \\
Y_{2} & =\text { perceived size }
\end{array}
$$

are obvious. The shape of the psychophysical function for heaviness/weight is given by Masin and Crestoni (1988) and resembles the plot (Gregson, 1988, chap. 3) for $\Gamma V 7$ with high $e$; the effects of size are neither a constant ratio nor a fixed decrement of the rated heaviness of the stimulus. This appears to confirm some attempts at model fitting by Cross and Rotkin (1975), which were variations on the ad hoc power functions advanced by J. C. Stevens and Rubin (1970). There are no paradoxical "cross-over" effects here.

This suggests that to model the size-weight illusion, values (in Equations 6 and 7) of $2.1<a_{1}<3.1$, $a_{2}>3, e \cong .3$, are viable, so $\lambda \cong 1$. Imbalance, in terms of $\lambda_{1} \neq \lambda_{2}$, is probably implicated, but the missing evidence on a weight-size illusion makes this point indeterminate. Modeling should not lose sight of the strong dominance of vision over kinesthesis in providing information to the human observer (Posner, Nissen, \& Klein, 1976); it is possible that such dominance would be reflected in asymmetrical cross-coupling.

\section{COMPENSATION AND OVERCOMPENSATION}

For dimension $i$, the range of $\lambda_{i}$, which covers all cases, from no compensation for the presence of other continua up to complete compensation, is

$$
e_{i} \leq \lambda_{i} \leq e_{i} \cdot \max \left(a_{h}\right), \quad h \neq i .
$$

Then,

$$
\lambda_{i}>e_{i} \cdot \max \left(a_{h}\right)
$$

is the range for overcompensation of cross-coupling effects.

In the case of complete compensation, the mappings

$$
U_{i} \rightarrow a_{i} \rightarrow 2 \Gamma \rightarrow Y_{i}(\operatorname{Re}, \mathrm{Im})
$$

would be almost exactly the same as a set of parallel uncoupled continua except for the effects of using Equation 7. This modification affects at least the sequential dynamics within loop evolution.

One may distinguish six cases, which are notionally easy to specify but actually only places in a continuum of the system's parameter values:

1. Uncoupled parallel continua with the same $\eta$.

2 . Uncoupled parallel continua with unequal $\eta$; a situation related to the conjecture of Posner et al. (1976) that vision takes longer to process information than other continua with which it may interact.

3. Coupled continua with no compensation, $\lambda_{i}=e_{i}$.

4. Coupled continua with fixed $\lambda, \eta$; the case typically graphed here in Figures 6 and 7.

5 . Coupled continua with perfect compensation; in effect fixed $e$ by making $\lambda$ variable.

6. Overcompensated continua in each case. This overcompensation necessarily can arise for some continua (the largest inputs) in (4), but not for all.

If (1) were to hold, then the results of single dimension experiments that are modeled by $\Gamma \vee 7$ would continue to be modeled in the same way for $n \Gamma$. Contrariwise, if (2) 
through (6) are possible, then, to find which is a most appropriate description of system dynamics, the matching in turn of a data set to all the alternative predictions is entailed.

Case 4 can be regarded as a very sluggish form of (5), if $\lambda$ is a variable and the system outer feedback very slowly adjusts for variations, from trial to trial, in $\max \left(a_{h}\right)$, to minimize cross-coupling. The time series $\left\{\lambda_{i}\right\}_{J}$ is a nonlinear function of the series $\left\{\Delta^{1} \max \left(a_{h}\right)\right\}$ and the observed result will float between $\Gamma\left(a_{i}, e_{i}\right)$ and $\Gamma\left[a_{i}, e_{i} \cdot \max \left(a_{h}\right)\right]$. That is, as the rate of sequential stimulus presentation is increased, the observed behavior should drift from (5) to (4).

Turning the argument around, the size-weight illusion, which is associated with patterns of data resembling (4), is expected to occur if the stimulus input rate of change $(d U / d t)$ exceeds the rate at which self-stabilization can occur in the cross-coupling of channels.

It apparently follows that the size-weight, and analogous illusions, could diminish with practice (which can happen), and that if it occurs at all it will be maximized with the simultaneous elicitation of judgments of size and weight. If adjustment of $\lambda$ is perfect (5), then the stimulus response plots of the output are a set of superimposed psychometric functions ( $\Gamma \vee 7)$, and if there is no weight- size illusion (the weight-size illusion can only be induced haptically and not through visual input), it is implied that the adjustment of $\lambda_{\text {size }}$ compensates fully for variations in $a_{\text {weight }}$.

\section{PREDICTIONS FROM THEORY}

In attempts to model a family of heaviness/weight plots with size as the third parameter, by using a family of power functions, Cross and Rotkin (1975) showed that the graphs of $\log$ (magnitude estimation of weight) against $\log$ (weight) fitted data for small volumes, but showed persistent small departures from linearity (which are usual in fitting power functions) for increasing volumes. This is just one of a series of like results already shown in Figure 2 and listed in Table 1 as "yes" in the last column. Figure 3 shows that a region of $Y_{1}, Y_{2}$ can be created which has properties analogous to the size-weight illusion. If the values of $\lambda_{1}, \lambda_{2}, \eta$ are held constant, but the ranges of $a_{1}$ and $a_{2}$ are reversed, predictions can be made about what would happen in a hypothetical weight-size illusion; a prediction for a local region is given in Figure 4. This hypothetical weight-size illusion appears to operate in an opposite sense; increasing the weight dimension increases the apparent size, but at the same time the psychophysi-

\section{Size-Weight Illusion Simulation in $2-\Gamma$}

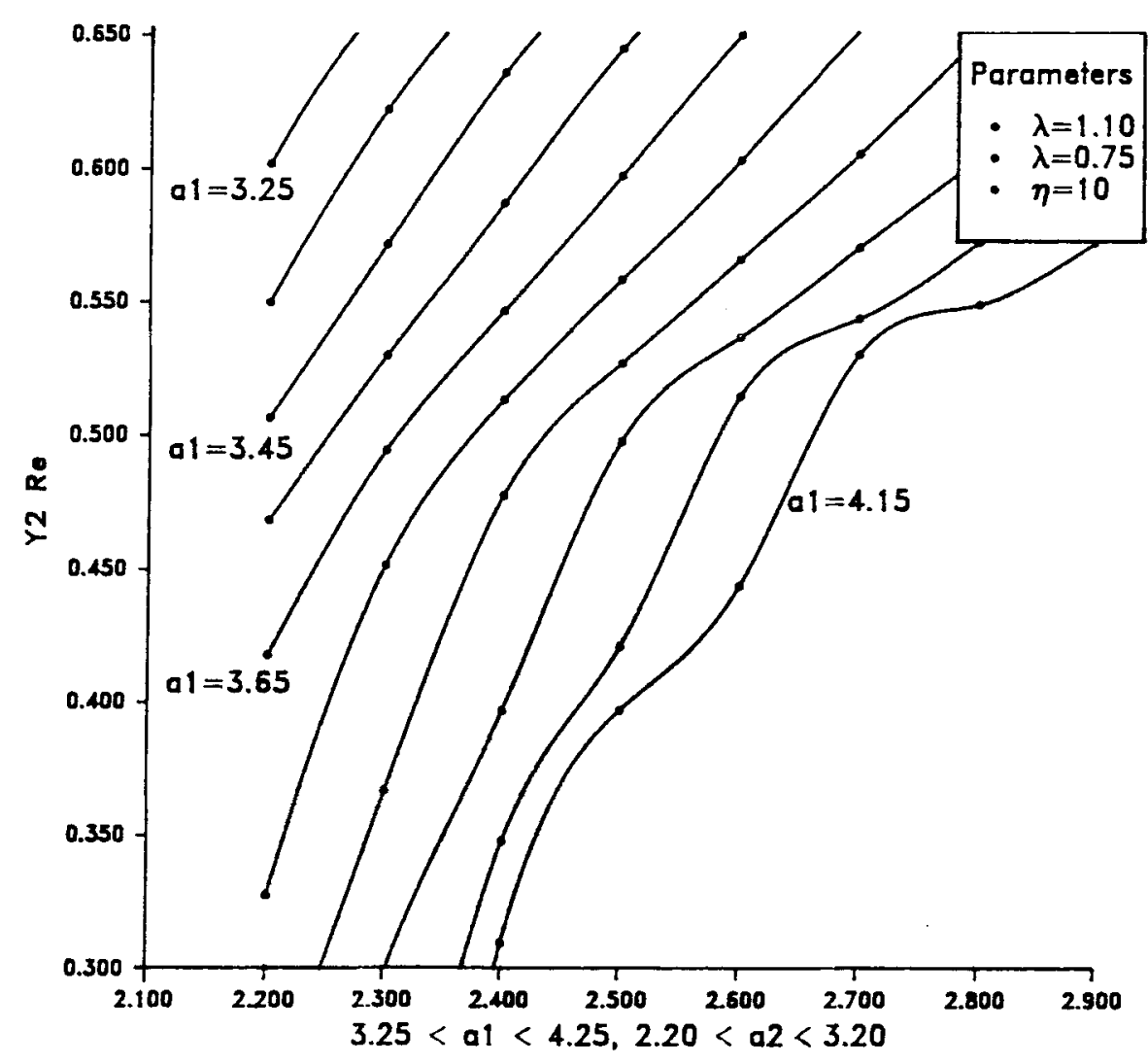

Figure 3. Theoretical curves from the process $2-\Gamma$, case 2, showing predicted regions of nonlinearity. 


\section{Weight-Size Illusion Simulation in $2-\Gamma$}

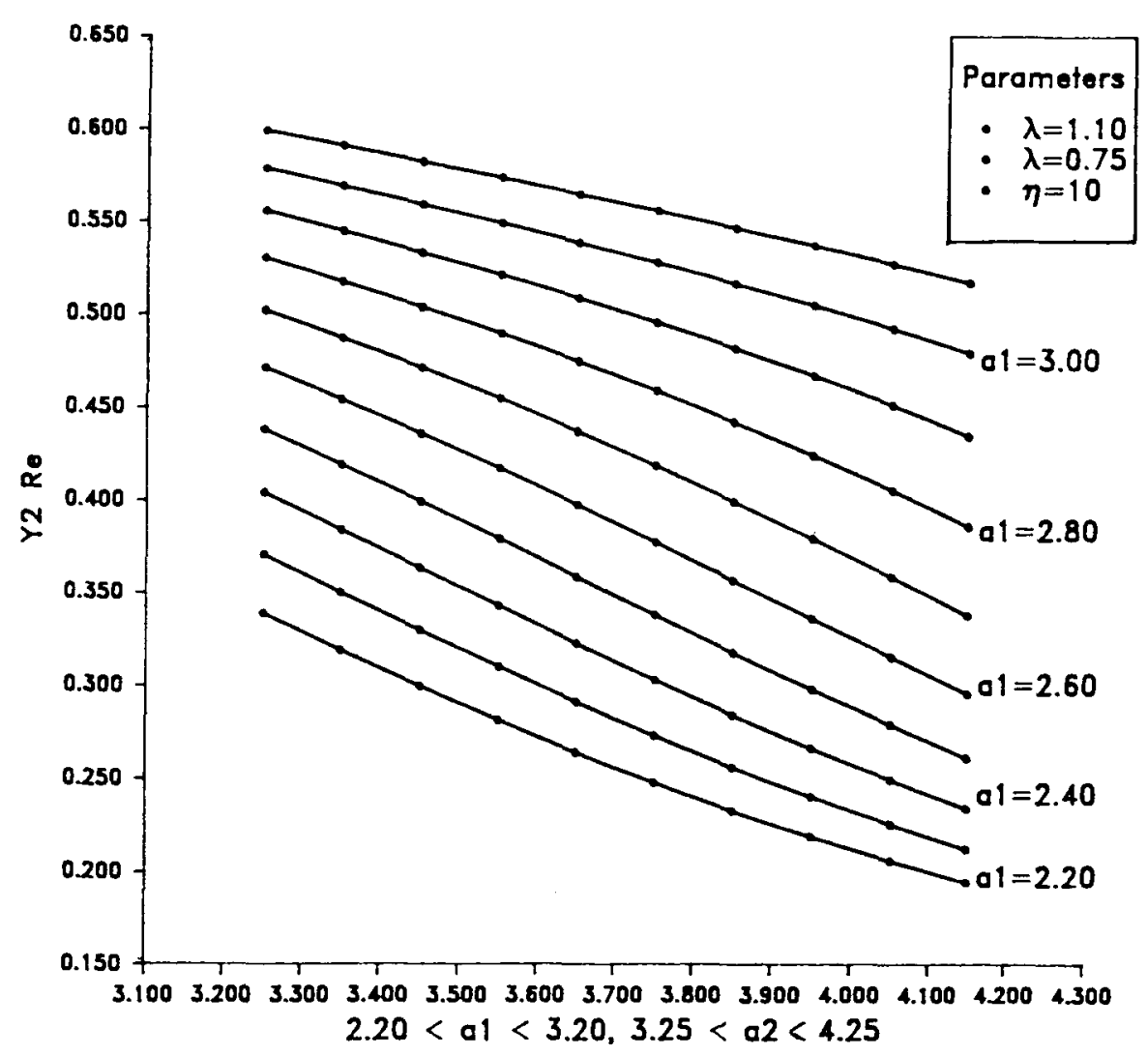

Figure 4. Theoretical curves with the roles of the dimensions interchanged, corresponding to Figure 3.

cal slope of apparent size on real size is negative. Both these predictions are testable, and so the model is, in principle, refutable for the range of parameter values used.

It may be relevant that in another intersensory interaction, that of vision and hearing, Radeau (1985) reported that vision "biassed" audition, but the effects of audition on vision were weak and variable from study to study; in her data, the effects of audition were sometimes reversed in direction, which corresponds to Figure 4 .

Because of a duality in the $a_{1}, a_{2}$ and $\lambda_{1}, \lambda_{2}$ pairs, the same result in Figure 4 could have been obtained by keeping the $a$ ranges the same and switching the $\lambda$ values; if both $a$ and $\lambda$ are switched about, we come back to the same plot as in Figure 3.

It has been remarked by some investigators that there is no good reason to categorize the size-weight illusion as in illusion, because it is an example of sensory dimension interaction, which in other cases, such as loudness and frequency in audition or color and apparent distance in vision, are not designated illusions but, rather, interaction effects. In the context of the present $2 \Gamma$ model, the predictions for all such cases would be derived from the same equations, but possibly with different parameter ranges.

\section{A NEW EXPERIMENT}

\section{Method}

Stimuli. Thirty-six opaque white cylinders, with flat sealed ends, all $43.2 \mathrm{~mm}$ in diameter, were constructed from plastic. ${ }^{3}$ No two tubes were exactly the same length or the same weight. The series of lengths, $\phi l$, were logarithmically spaced, and the weights $\phi w$ made of a random component from a logarithmically composed series, added to the weight of the cylinder which was directly proportional to its length. The ranges were

$$
\begin{aligned}
& 42.5 \mathrm{~mm}<\phi l<260.5 \mathrm{~mm}, \\
& 81.8 \mathrm{~g}<\phi w<360.4 \mathrm{~g}, \\
& \text { with } r_{l w}=+.541 .
\end{aligned}
$$

So this series constitutes an intermediate case between $T(s w)=0$ and $T(s w)=\min [H(w), H(\mathrm{~s})]$, and if judgments are proportional to real weights, they will necessarily also be proportional to the cylinder lengths, but correlated less.

The internal distribution of mass within each cylinder was constructed so that the center of gravity was located, as nearly as possible, at the middle of each of the three orthogonal dimensions.

Procedure. A subject sat with his/her preferred elbow resting comfortably on a table and with the outstretched palm uppermost. The cylinders were lowered gently onto the subject's palm, with their centers of gravity over the middle of the palm, and likewise removed after judgments had been elicited. 
Table 2

Fitted Model Values for Each Subject

\begin{tabular}{|c|c|c|c|c|c|c|c|c|c|c|c|c|}
\hline \multirow[b]{2}{*}{ Subject } & \multirow[b]{2}{*}{ Sex } & \multirow[b]{2}{*}{ Order } & \multicolumn{2}{|c|}{$Y_{w}$} & \multicolumn{2}{|c|}{$Y_{l}$} & \multirow[b]{2}{*}{$\lambda_{1}$} & \multirow[b]{2}{*}{$\lambda_{2}$} & \multirow{2}{*}{$\begin{array}{l}v(2 \Gamma \mid \min E) \\
v(\psi \phi \mid \text { data })^{-1}\end{array}$} & \multirow[b]{2}{*}{$r_{1}$} & \multirow[b]{2}{*}{$r_{2}$} & \multirow[b]{2}{*}{$r_{3}$} \\
\hline & & & Slope & Int. & Slope & Int. & & & & & & \\
\hline 1 & F & $w, l$ & .923 & .006 & -.096 & .167 & 0.70 & 1.05 & 1.39 & .622 & .496 & -.041 \\
\hline 2 & $\mathrm{~F}$ & $1, w$ & .923 & .009 & -.315 & .338 & 0.70 & 1.00 & 1.34 & .634 & .550 & .002 \\
\hline 3 & $\mathrm{M}$ & $w, 1$ & .863 & .015 & -.228 & .259 & 0.70 & 1.00 & 1.37 & .719 & .581 & -.041 \\
\hline 4 & $\mathbf{M}$ & $1, w$ & .538 & .053 & .417 & -.161 & 0.70 & 1.00 & 0.25 & .895 & .540 & .456 \\
\hline 4 & $\mathbf{M}$ & RVN & .981 & -.0003 & .741 & .017 & $e=.75$ & $e=.30$ & 1.001 & .895 & .540 & .456 \\
\hline 5 & $\mathrm{~F}$ & $1, w$ & .679 & .046 & -.287 & .310 & 0.70 & 1.00 & 1.36 & .745 & .513 & .094 \\
\hline 6 & $\mathbf{M}$ & $1, w$ & .296 & .054 & .080 & .029 & 0.65 & 1.10 & 0.25 & .502 & .508 & .236 \\
\hline 7 & $\mathbf{F}$ & $w, l$ & .812 & .033 & -.341 & .348 & 0.70 & 1.00 & 1.51 & .785 & .515 & .090 \\
\hline 8 & $\mathrm{~F}$ & $1, w$ & .858 & .025 & -.123 & .197 & 0.70 & 1.05 & 1.41 & .725 & .539 & .097 \\
\hline 9 & F & $w, 1$ & .772 & -.451 & -.389 & .038 & 0.70 & 1.00 & 0.12 & .832 & .523 & .426 \\
\hline 10 & $\mathbf{M}$ & $1, w$ & .773 & .035 & -.002 & .037 & 0.70 & 1.00 & 1.09 & .755 & .559 & .146 \\
\hline 11 & $\mathbf{M}$ & $w, 1$ & .536 & .053 & - & - & 0.70 & 1.00 & 0.73 & .781 & .479 & .317 \\
\hline 12 & $\mathbf{F}$ & $1, w$ & .346 & .074 & -.156 & -.007 & 0.70 & 1.00 & 0.14 & .760 & .505 & .338 \\
\hline 13 & $\mathbf{M}$ & $w, l$ & .811 & .034 & -.022 & .049 & 0.70 & 1.00 & 1.47 & .779 & .525 & .131 \\
\hline 14 & $\mathbf{M}$ & $1, w$ & .495 & .059 & -.216 & .094 & 0.70 & 1.05 & 0.32 & .792 & .554 & .330 \\
\hline
\end{tabular}

Note- "Order" refers to judgments of size and weight elicited on a trial $(w=$ weight, $l=$ length). Int. $=$ intercept, RVN $=$ revised $\mathrm{C} 1$ analysis.

The whole series of 36 cylinders was presented in random order, at carefully paced 20 -sec intervals, and to each cylinder the subject gave estimates of both perceived weight $(\psi w)$ and perceived length $(\psi l)$, the order of elicitation being balanced, with half the subjects doing the judgments in the reverse order. The regression of perceived on real weight is almost linear in the ranges used here (Baker \& Dudek, 1955) if there is no confounding with size. The trials were evenly spaced in time, once every $20 \mathrm{sec}$.

To induce some consistency in the use of units given by subjects in making their responses, initially one cylinder was presented and the subjects were informed of its approximate length $(200 \mathrm{~mm})$ and approximate weight $(300 \mathrm{~g})$.

Data analysis. 1 . The data are most directly analyzed by estimating the regression parameters $\alpha, \beta, \gamma$ in

$$
\psi w=\alpha \cdot \phi w+\beta \cdot \phi l+\gamma \cdot \psi l
$$

and, if necessary, adding in a nonlinear $l, w$ term or terms; the previous attempts by Anderson (1982) and others to model the situation suggest that this would be expedient if no other prior model were available.

2. As the experiment is strictly a generator of a 2-input-2-output time series, $m$ trials long, it could be modeled, again with linearity assumptions, as shown by Gregson (1984).

3 . We may proceed directly to fitting the model $2 \Gamma$ shown in Figure 3, matching the theory and data by introducing affine transformations,

$$
\phi l \rightarrow a_{1}, \quad \phi w \rightarrow a_{2},
$$

and then minimizing a loss function on the $a_{1}, a_{2}, Y_{1}$ space as plotted in Figure 3. This is

$$
E=\sum_{j=1}^{m} \delta_{k}^{2},
$$

where

$$
\delta_{j}^{2}=\left[a_{i j}-\hat{\alpha} \cdot \phi w_{j}-\hat{\beta}\right]^{2}+\left[Y_{1}(\mathrm{Re})-\chi \cdot \psi w_{i j}-\hat{\xi}_{1}\right]^{2},
$$

which is a minimization of the interpoint distances of the computed theoretical and observed coordinates in the two spaces $\{a, Y(\operatorname{Re})\}$ from $2 \Gamma$ and $\{\phi w, \psi w\}$ from the data. The constants $\hat{\alpha}, \hat{\beta}, \hat{\chi}, \hat{\xi}$ are to convert real units (grams, responses) into the arbitrary $a, Y$ units of the model using Equation 12.

It should be noted that it is meaningless to pool data over subjects in (2) and (3) above, and that the existence of nonlinearities strictly invalidates the use of a linear model in (1) unless it can be shown that the nonlinearities appear in the same range of stimulus parameters for each observer whose data are pooled. The latter condition appears not to have been shown to hold in any published studies we have examined.

\section{Results}

The results are summarized for each subject separately in Table 2 . The values of $\lambda$ are only estimated in steps of .05. The columns reading from left to right give subject, sex, order in which judgments of size and weight were elicited on a trial, the slope and intercept of the regression of fitted minres $Y$ on responses $\hat{Y}_{w}$, and on $\hat{Y}_{l}$, the $\lambda$ values for the minres solution in $2 \Gamma$, the ratio of variance fitted by $2 \Gamma$ divided by that fitted by a direct linear regression of observed responses on stimuli, and three correlations between physical weight, perceived weight, and perceived length, as estimated. These are $r_{1}$ $=r_{\phi w . \psi w}, r_{2}=r_{\phi w . \psi l}, r_{3}=r_{\psi w . \psi l}$. The expected values of these correlations are also deducible for both the size-weight illusion and veridical perception; one of the regressions for Subject 11 was not calculated because it took up negligible variance.

We may see that subjects vary considerably in the extent to which they show behavior consistent either with the size-weight illusion or with the $2 \Gamma$ model, and using the parameter values chosen for the simulation, the model fits closest those subjects who show the illusion most clearly. If the model assuming the size-weight illusion fits optimally (see Equation $S 9$ in Appendix B), then $Y_{w}$ slope $\rightarrow 1, Y_{w}$ intercept $\rightarrow 0$, and $Y_{l}$ slope should become negative. If complete size-weight illusion occurs, then $r_{1}$ drops to about $+.54, r_{3}$ becomes in the limit negative, and in any case less than +.54 if only a partial size-weight illusion occurs. If perception is veridical, then $r_{1}=+1$, $r_{2}=+.54$, and $r_{3}=+.54$ with the stimulus series used here. These properties of the correlations follow without committment to any one model; they arise from the construction of the stimulus series.

Subject 4 in Table 2 clearly judges weight almost objectively; it should therefore be possible to model his be- 


\section{Size-Weight data analysis Subj. 4 Revision}

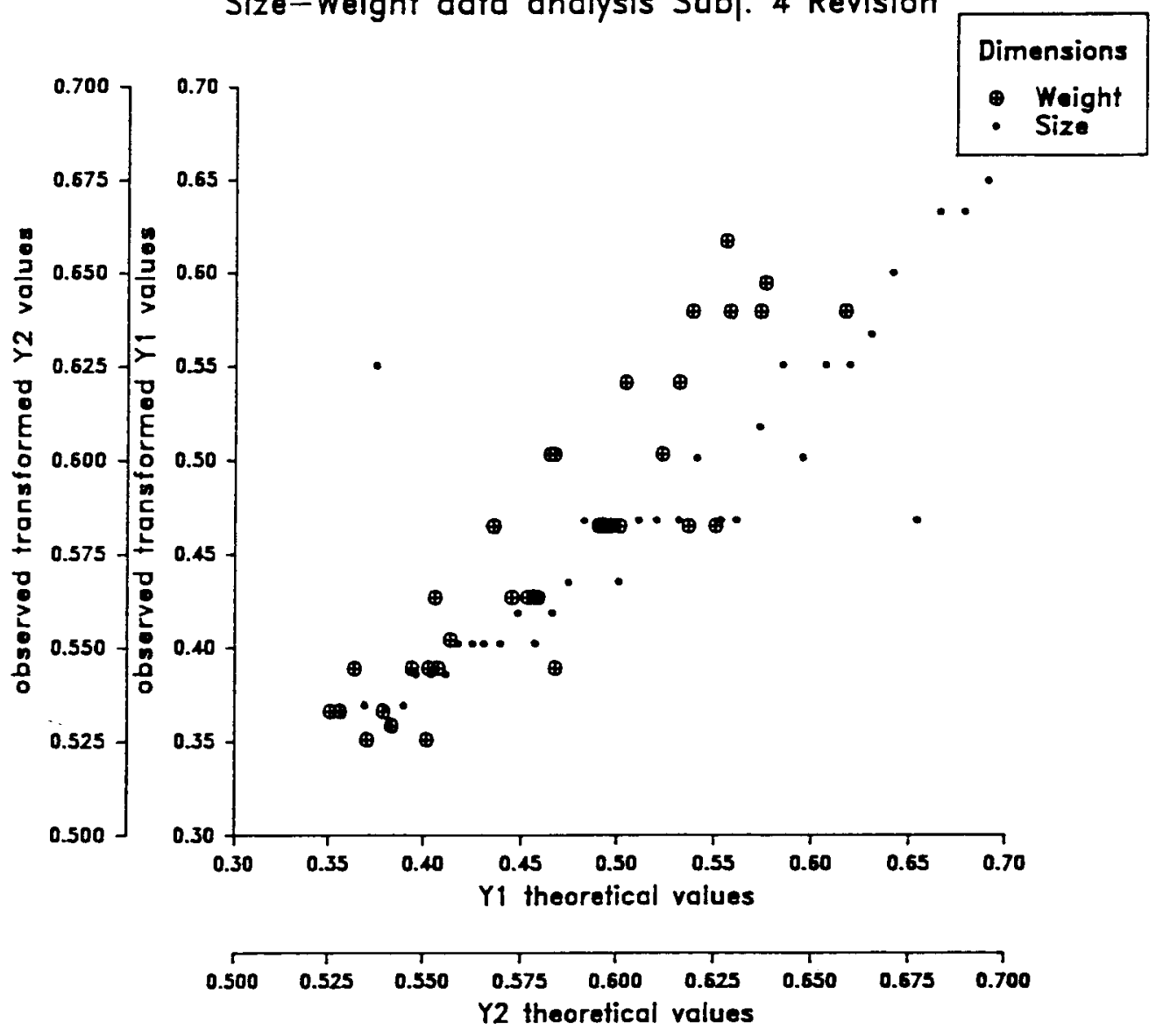

Figure 5. Single responses for Subject 4 with $2-\Gamma$, case 1 fitted, showing no evidence of the illusion.

havior into a $2 \Gamma$, case 1 parameter set, and the results are shown in the line marked RVN and in Figure 5. Subjects $9,11,12$, and 14 also fit veridical perception better than the size-weight prediction. For contrast, plots for Subjects 9 and 13 are given in Figures 6 and 7 . Multiple points are superimposed.

It should be especially noted that the points plotted in these graphs of individual results are single responses, and not averaged responses as is the more usual practice in published work, in order to smooth out errors treated as arising at a response selection stage in the process. Some subjects use so few alternative numbers in their response selection that data are degenerated $[H(\psi w) \ll$ $\mathrm{H}(\phi w)]$, so that no model which assumes that the responses are based on a continuum of $Y$ values can fit very closely.

It is seen that $2 \Gamma$ without cross-coupling fits very well to these data, comparably to $2 \Gamma$ with cross-coupling for the first 3 subjects. Subject 6 fits neither model very well.

The graphs for subjects who show the size-weight illusion were selected as examples. It is clear that $\psi w$ responses are predicted and $\psi l$ responses are erroneously estimated if we use Equations 11 and 12. This is exactly what should be expected in case 2, for two reasons; the estimation procedure only minimizes errors on the weight dimension, and more significantly, the $2 \Gamma$ model predicts that if $\psi w$ is elicited as a response, we will get one pattern, but if $\psi l$ is elicited, we should get quite another; in short, asking for weight should produce the size-weight illusion, but asking for length should produce the weightsize complementary illusion. As has already been noted, they are two different parameter constellations in $2 \Gamma$, case 2 , but only one constellation in case 1 .

Here there are, in fact, at least four possible experiments to be distinguished, each imposing a different demand function in the judgment task. These are: (1) estimate only $\phi w$ by $\psi w$, without the availability of visual or haptic cues, (2) estimate only $\phi l$ without lifting or touching the objects, (3) estimate $\phi w$ by $\psi w$ with $\phi l$ present but not judged (the situation for many of the experiments in Table 1), and (4) estimate both $\phi w$ and $\phi l$ by eliciting both $\psi w$ and $\psi l$ with all sensory cues available, as is done here.

The $2 \Gamma$ model predictions distinguish the alternative demand characteristics of the task situation: the two different mappings as illustrated in Figures 3 and 4 cannot both 


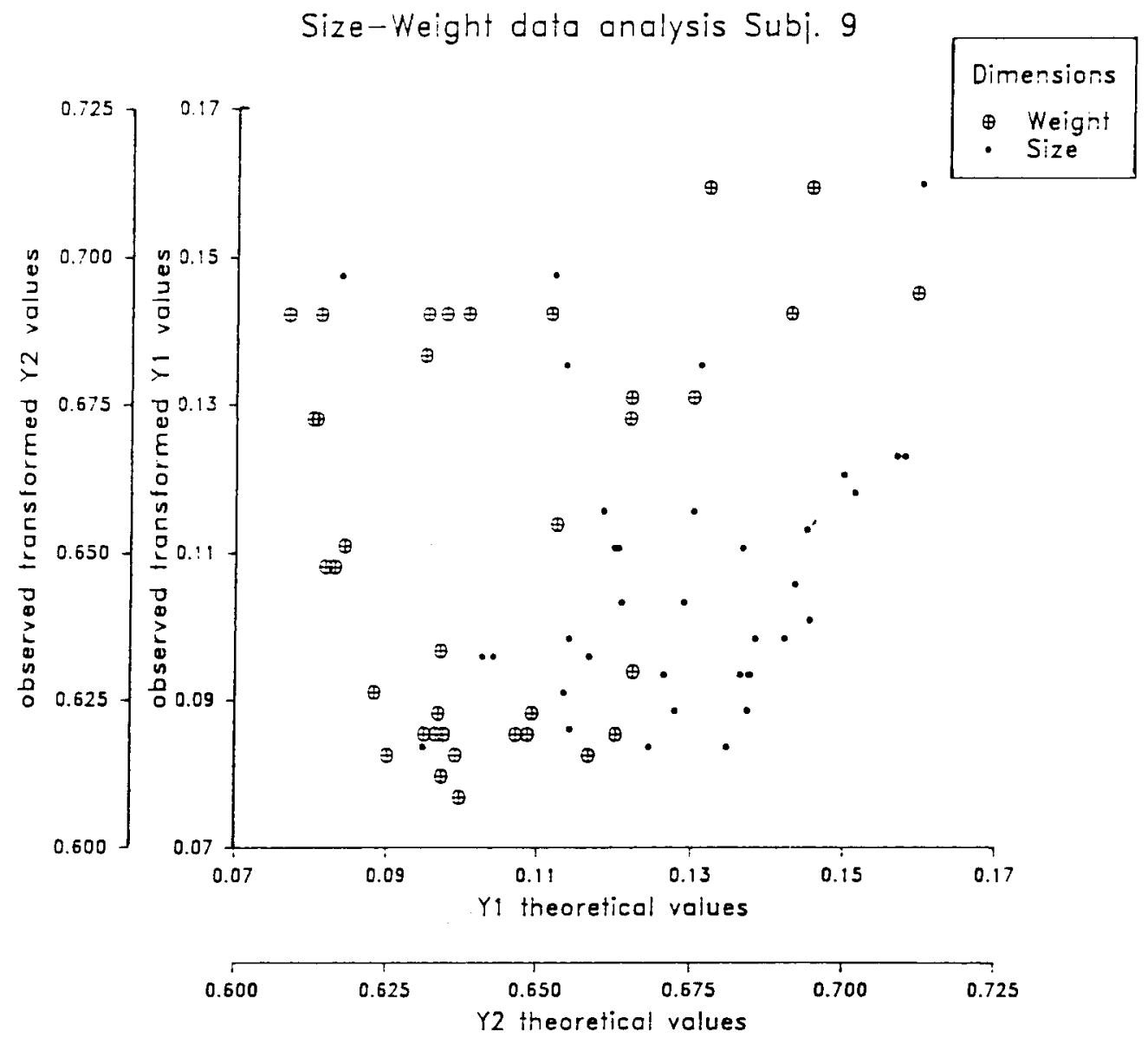

Figure 6. Single responses for Subject 9 with $2-\Gamma$, case 2 fitted, showing weak evidence of the illusion.

be elicited at the same time, and the observer must be able to switch very rapidly between them. Consequently, a new table corresponding to Table 2 would be needed to fit the length judgments of $2 \Gamma$ in a minimization analogous to Equations 11 and 12.

\section{DISCUSSION}

The position taken here is perhaps radical; an illusion is definable as a closed set of mappings from multivariate stimuli onto responses in which invariances in the mappings are not preserved, in contradistinction to normal, veridical perception. In veridical perception, we expect to find that the perceived stimulus magnitudes are directly proportional to the physical stimulus values on the dimensions used, at least in terms of central response tendencies within some second-order random perturbations. Seeing things as they are, subject to scaling of the units in which responses are expressed, holds up sufficiently for the approximate laws associated with the names of Fechner and Stevens to be useful descriptions in unidimensional psychophysics. By using a nonlinear model of interdimen- sional interaction, $2 \Gamma$, we can drop the idea that this set of mappings is closed; the core equation of the nonlinear model will for some of its parameter values generate at least two relatively unstable outputs. Because it is a cubic recursion, it has also another property (May, 1984): there are two distinct paths towards chaotic dynamics which it can follow as soon as it goes into multiple representations of the inputs in its outputs. We should expect, therefore, that at least two distinct forms of responding, one veridical and the other associated with strong crosscoupling between dimensions, could coexist. The stability of each would be unpredictable given the underlying chaotic dynamics induced by strong imbalance in the two physical inputs.

In this context, illusions as a special sort of odd perceptions do not exist, and the conditions for the creation of illusions are not definable as bounded or as functions of some (vectors of) stimulus values. Instead, it follows directly from the nonlinearity of the system that if inputs are sufficiently imbalanced, or cross-coupled, then the process can move into nonveridical input-output mappings, because of phase changes in the internal dynamics 


\section{Size-Weight data andysis Subj. 13}

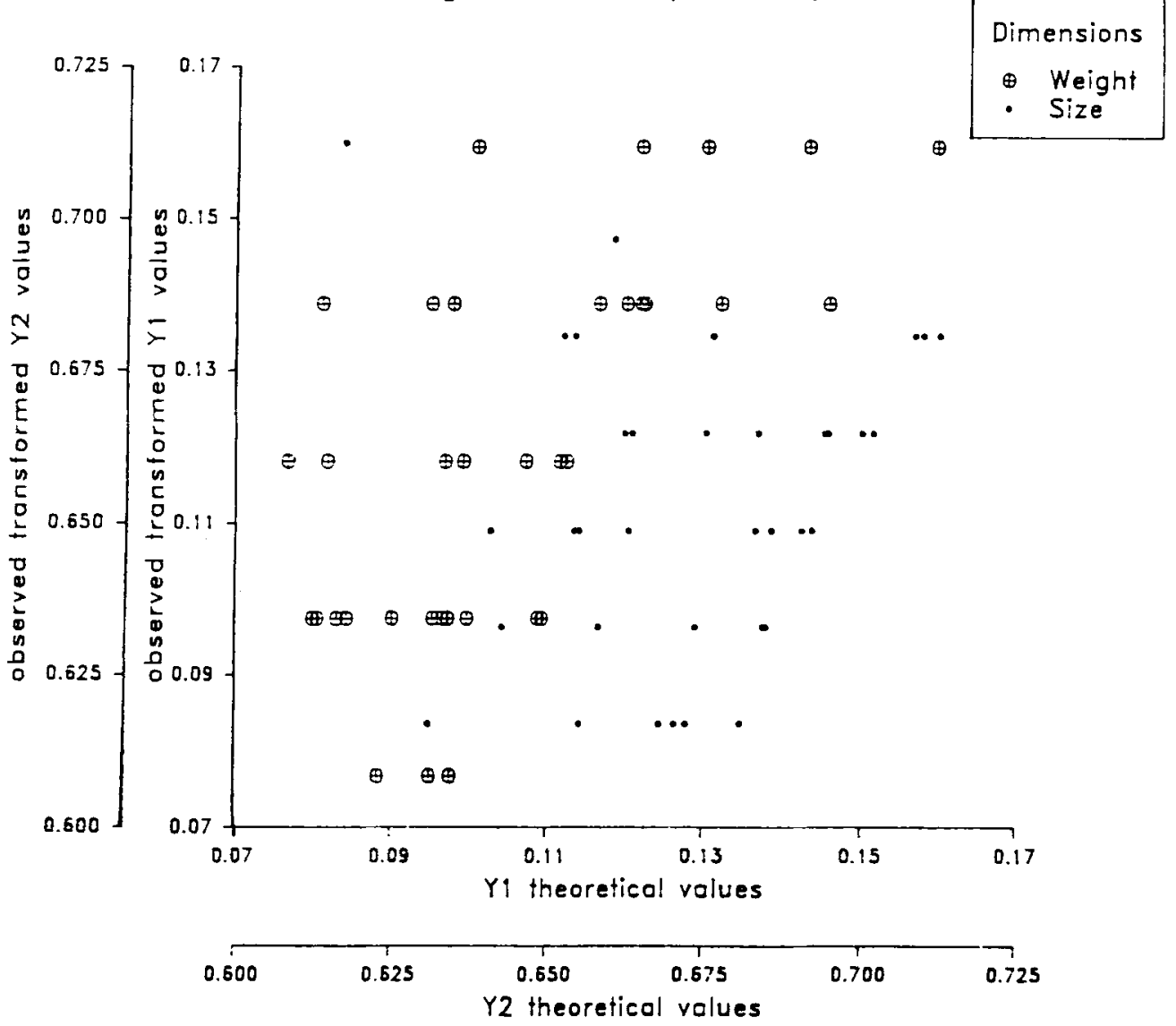

Figure 7. Single responses for Subject 13 with $2-\Gamma$, case 2 fitted, showing evidence of the illusion, but restricted use of response levels.

of one or more component dimensions which each, if it were functioning in isolation as a unidimensional psychophysical transformation, would be approximately linear over a restricted range.

It follows that doing experiments on carefully controlled single-variable changes, in the tradition of 19th century physics, is sufficient to destroy precisely the information about nonlinearity in the psychophysical system that gives us insight as to why, under some conditions, perception produces what are, to the external perspective of the phenomenological theorist, illusions. We do not deny that illusions exist, nor do we assert that only one process $(2 \Gamma$, case 2) for producing them arises, but we think that their metatheoretical status is wrongly conceived if we start from the false premise that multidimensional psychophysics is linear. In a way, we find ourselves siding with Gibson's hope that perception could someday be reducible to some sort of complicated psychophysics. We part company with Gibson in asserting here that the psychophysics is not necessarily complicated (to those who can look at the problem with the tools of nonlinear systems theory) but it is very subtle, and the intervening variables are not metaphors for some of the apparent components of everyday phenomenology.

As the data here suggest, in concordance with many previous studies, that the size-weight illusion is not always present, an analysis with some penetration into the system dynamics would go further than is achieved here. We have assumed that the process is not linear, and then shown that this assumption is consistent with data series, but to do this we have also assumed that stationarity within a subject within a session holds. It is not necessary to make the stationarity assumption; in theory, each single response could be matched to two distinct predictions-one from $2 \Gamma$, case 1 (uncoupled continua) and the other from $2 \Gamma$, case 2 (cross-coupled continua). By using recursive filtering, such as two Kalman filters (Gregson, 1983), one on each of the two competing models, we could address the question of stationarity, over time, of behavior in terms of its consistency with the size-weight illusion, and examine individual differences from that perspective. In such an analysis we can calculate a likelihood ratio for the 
size-weight illusion on each trial, given $2 \Gamma$ as the basic generating process. Such analyses are computationally more advanced and will be pursued elsewhere.

\section{REFERENCES}

ANDERSON, N. H. (1967). Application of a weighted averaging mode to a psychophysical averaging task. Psychonomic Science, 8, 227-228.

ANDERSON, N. H. (1970). Averaging model applied to the size-weight illusion. Perception \& Psychophysics, 8, 1-4.

ANDERSON, N. H. (1972). Cross-task validation of functional measurement. Perception \& Psychophysics, 12, 389-395.

ANDERSON, N. H. (1982). Methods of information integration theory. New York: Academic Press.

ANDERSON, N. H., \& JACOBSON, A. (1968). Further data on a weighted average model for judgment in a lifted weight task. Perception \& Psychophysics, 4, 81-84.

BAKER, K. E., \& DUDEK, F. J. (1955). Weight scales from ratio judgments and comparisons of existent weight scales. Joumal of Experimental Psychology, 50, 293-308.

Başar, E., Flohr, H., Haken, H., \& Mandell, A. J. (1983). Synergetics of the brain (Springer Series in Synergetics, Vol. 23). Berlin: Springer-Verlag.

Birnbaum, M. H., VeIt, C. T. (1974). Scale-free tests of an additive model for the size-weight illusion. Perception \& Psychophysics, 16, 276-282.

Bolton, F. E. (1898). A contribution to the study of illusion, with special reference to (a) the effect of size upon estimations of weight, (b) the effect of contour upon estimations of area. American Journal of Psychology, 9, 167-177.

BREDENKAMP, J. (1984). Theoretische und experimentelle Analysen einiger Wahrnehmungstäuschungen. Archiv für Psychologie, 136, 281-291.

BRUNSWIK, E. (1933). Untersuchungen über Wahrnehmungsgenstande: I-IV. Archiv für gesamte Psychologie, 88, 377-397.

Caianiello, E. R. (Ed.) (1987). Physics of cognitive processes. Singapore: World Scientific.

Camprell, E. A., Gregson, R. A. M. (in press). Julia sets for the gamma recursion in nonlinear psychophysics. Acta Mathematicae Applicandae.

Charpentier, A. (1891). Analyse expérimentale de quelques élements de la sensation de poids. Archives Physiologiques Normales et Pathologiques, 3, 122-135.

Claparède, E. (1902). La vitesse du soulèvement des poids de volumes différents. Archives de Psychologie, 1, 69-94.

Cross, D. V., \&otkin, L. (1975). The relation between size and apparent heaviness. Perception \& Psychophysics, 18, 79-87.

DAvis, C. M. (1973). Mechanical advantage in size-weight illusion. Perception \& Psychophysics, 13, 238-240.

DAvis, C. M., \& BRicketT, P. (1977). The role of preparatory muscular tension in the size-weight illusion. Perception \& Psychophysics, 22, 262-264.

Davis, C. M., TAYlor, M., \& Brickett, P. (1977). A weight illusion produced by lifted movements. Perceptual \& Motor Skills, 44, 299-305.

Feder, J. (1988). Fractals. New York: Plenum.

FISCHEL, H. (1926). Transformationserscheinungen bei Gewichtshebungen. Zeitschrift für Psychologie, 98, 342-365.

FLournoy, T. (1894). De $L$ 'influence de la perception visuelle des corps sur leur poids apparent. L'Année Psychologique, 1, 198-208.

Freeman, I., \& ADAM, J. (1965). Size-weight illusion and anchoring of weight judgments. Perceptual \& Motor Skills, 20, 63-68.

FRIEDLÄNDER, H. (1920). Über Gewichtstäuschungen. Zeitschrift für Psychologie, 84, 143, 179.

Fries, I., \& HoLmberG, L. (1967). The psychophysics of the size-weight illusion: I. Functional relation between heaviness and volume estimation. Psychological Bulletin (Lunds Universitet, Sverige), 7, 1-20.

FURTH, H. G., (1960). The effects of the size-weight illusion on adaptation level. Journal of Experimental Psychology, 60, 150-154

GLEICK, J. (1987). Chaos: Making a new science. New York: Viking
Gregory, R. L., \& Ross, H. E. (1967). Arm weight, adaptation and weight discrimination. Perceptual \& Motor Skills, 24, 1124-1130.

Gregson, R. A. M. (1983). Time series in psychology. Hillsdale, NJ: Erlbaum.

GrEGSON, R. A. M. (1984). Invariance in time series representations of 2-input 2-output psychophysical experiments. British Journal of Mathematical \& Statistical Psychology, 37, 100-121.

Gregson, R. A. M. (1988). Nonlinear psychophysical dynamics. Hillsdale, NJ: Erlbaum.

Gregson, R. A. M. (1989a, August). Nonlinear psychophysics of binary mixtures. Paper presented at the European Mathematical Psychology Meeting, Catholic University of Nijmegen, Netherlands.

Gregson, R. A. M. (1989b). A nonlinear systems approach to Fechner's paradox. Biological Cybernetics, 61, 129-138.

Gregson, R. A. M. (1989c). Response latencies in nonlinear psychophysics. Manuscript in preparation.

GREGSON, R. A. M., \& BRITTON, L. A. (1989). Isointensity and hypoaddition in odour binary mixtures. Manuscript submitted for publication.

Gumowski, I., \& MirA, C. (1980). Dynamique chaotique. Toulouse: Cepadues Éditions.

HAO, B.-L. (1984). Chaos. Singapore: World Scientific

HARPER, R. S., \& STEVENS, S. S. (1948). A psychological scale of weight and a formula for its derivation. American Journal of Psychology, 61, 343-366.

Harshfield, S. P., \& DeHardt, D. C. (1970). Weight judgment as a function of apparent density of objects. Psychonomic Science, 20, 365-366.

Huang, I. (1945a). The size-weight illusion in relation to the perceptual constancies. Journal of General Psychology, 33, 43-63.

Huang, I. (1945b). The size-weight illusion and the "weight-density illusion." Joumal of General Psychology, 33, 65-84.

JEFFREYS, H. (1961). Theory of probability (3rd ed.). Oxford, England: Oxford University Press.

Jones, L. A. (1986). Perception of force and weight: Theory and research. Psychological Bulletin, 100, 29-42.

Kolehmainer, K., MikKonen, V. (1970). Apparent weight differences as a source of after-effects. Scandinavian Journal of Psychology, 11, 161-166.

KoselefF, P. (1936). Eine Modifikation des "Charpentier-Effektes." Psychologische Forschung, 23, 142-145.

Koseleff, P. (1957). Studies in the perception of heaviness. Acta Psychologica, 13, 242-252.

KREUZER, E. (1987). Numerische Untersuchung nichtlinearer dynamischer Systeme. Berlin: Springer-Verlag.

Livi, R., Ruffo, S., Ciliberto, S., \& Buiatri, M. (1988). Chaos and complexity. Singapore: World Scientific.

Loomis, H. N. (1907). Reaction to equal weights of unequal size. Psychological Monographs, 8, 334-348.

MAsin, S. C., \& CREstoni, L. (1988). Experimental demonstration of the sensory basis of the size-weight illusion. Perception \& Psychophysics, 44, 309-312.

MAY, R. M. (1984). The cubic map in theory and practice. Nature, $311,13-14$.

Nyssen, R., \& Bourdon, J. (1955). Contribution to the study of sizeweight illusion by the method of P. Koseleff. Acta Psychologica, 11, 467-474.

OberLin, K. W. (1936). Variation in intensive sensitivity to lifted weights. Journal of Experimental Psychology, 19, 438-455.

OOstlander, A. M. (1967). The development of the weight-volume illusion. Journal of Experimental Child Psychology, 5, 237-248.

OTt ANDER, C. (1967). On sensory interaction in judgment of velocity and its measurement by psychophysical methods. Stockholm: Häggströms Tryckeri.

Posner, M. I., Nissen, M. J., \& Klein, R. M. (1976), Visual dominance: An information-processing account of its origins and significance. Psychological Review, 83, 157-171.

Press, S. J. (1989). Bayesian statistics: Principles, models and applications. New York: Wiley.

Price, I. R., \& Gregson, R. A. M. (1988). Nonlinear dynamics in a complex cubic one-dimensional model for sensory psychophysics. Acta Mathematicae Applicandae, 11, 1-17. 
Prigogine, I., Stengers, 1. (1984). Order out of chaos. London: Heinemann.

QUASTLER, H. (Ed.) (1955). Information theory in psychology. Glencoe, IL: Free Press.

RADEAU, M. (1985). Signal intensity, task content, and auditory-visual interactions. Perception, 14, 571-577.

Robinson, H. B. (1964). An experimental examination of the size-weight illusion in young children. Child Development, 35, 91-107.

Ross, H. E. (1966). Sensory information necessary for the size-weight illusion. Nature, 212, 650.

Ross, H. E. (1969). When is weight not illusory? Quarterly Journal of Experimental Psychology, 21, 346-355.

Ross, H. E., \& Gregory, R. L. (1970). Weight illusion and weight discrimination-a revised hypothesis. Quarterly Joumal of Experimental Psychology, 22, 318-328.

RUle, S. J., \& Curtis, D. W. (1976). Converging power function as a description of the size-weight illusion: A control experiment. Bulletin of the Psychonomic Society, 8, 16-18.

Schuster, H. C. (1984). Deterministic chaos. Weinheim: PhysikVerlag.

SuöBERG, L. (1969). Sensation scales in the size-weight illusion. Scandinavian Journal of Psychology, 10, 109-112.

Smithson, M. (1988). Has psychology inherited the wrong mathematics? In T. Zétényi (Ed.), Fuzzy sets in psychology (pp. 1-32). Amsterdam: Elsevier.

Stevens, J. C., Rubin, L. L. (1970). Psychophysical scales of apparent heaviness and the size-weight illusion. Perception \& Psychophysics, 8, 225-230.

Thouless, R. H. (1931a). Phenomenal regression to the real object: I. British Journal of Psychology, 21, 339-359.

THOULESS, R. H. (1931b). Phenomenal regression to the real object: II. British Journal of Psychology, 22, 1-30.

UsNadze, D. (1931). Uber die Gewichtstäuschung und ihre Analoga. Psychologische Forschung, 14, 366-379.

WigGiNs, S. (1988). Global bifurcations and chaos. New York: SpringerVerlag.

Wolfe, H. K. (1898). Some effects on size judgments of weight. Psychological Review, 5, 25-55.

\section{NOTES}

1. Usnadze (1931) states (p. 371) that "Bei offenen Augen tritt die Volumtäuschung nicht auf, weil offenbar die optische Grössengleichheit der beiden Küglen zu deutlich und unbeeinflussbar ist," but can exist if size is perceived haptically. It is pertinent that the stimuli he used were small spheres, and not cylinders or rectilinear solids, which being easier to make are more usually used.

2. In reference back to Gregson (1988), the form of the $\Gamma V 7$; there are, in fact, a family of models based on $\Gamma$, and the ones used here is one of the simplest.

3. These were constructed to exact specifications $( \pm 1 \mathrm{~mm}, \pm 1 \mathrm{~g}$ ) by J. Reid and C. Lisle in the Psychology Departmental Workshop at the University of New England.

4. Professor R. H. Day kindly made available copies of the original papers by Charpentier (1891) and by Flournoy (1894), drawing our attention to the existence of the latter. Flournoy (1894) was apparently the first investigator to treat the problem by what would now be called magnitude estimation; he asked subjects to estimate weights directly in grams, and noted large individual differences in their ability to do this accurately, depending on whether their education was scientific or literary.

\section{APPENDIX A \\ INFORMATION STRUCTURE OF EXPERIMENTAL SITUATIONS}

Most of the experimental designs in the literature have created a small set of evenly spaced weights and/or a comparable set of volumes, holding weight constant and varying volume, or the reverse (e.g., Cross \& Rotkin, 1975), which makes an analysis of variance (ANOVA) approach easy (Anderson, 1970,
1982) at the expense of reducing the diversity of presented objects so that some can become recognizable as repeated presentations within the time course of an experimental session. An ANOVA approach is, of course, wrong on two counts; it destroys stimulus information, and it is linear and can produce only uninterpretable interactions, the clearest case of which is (apparently unintentionally) given by Anderson (1982).

Using information-theory measures, where $H$ is the information in bits of a closed set of alternatives and $T$ is transmitted information between two such sets (see Quastler, 1955, for formal definitions), and treating the task as interdimensional transfer, Charpentier's (1891) original observation, ${ }^{4}$ with two stimuli, is (denoting physical magnitudes as $s, w$ and perceived weight as $\psi w)$

$$
H(w)=0, \quad H(s)=1, \quad T(s w)=0,
$$

because $T(s w) \ngtr \min [H(w), H(s)]$.

Experiments with a lattice of $m \times n$ sizes and weights

$$
\begin{aligned}
& H(w)=\log _{2} n \\
& H(s)=\log _{2} m
\end{aligned}
$$

and if the lattice is complete, $T(s w)=0$, because completeness implies a maximum $H(s w)$, with equiprobable stimulus presentation.

For a subset of the lattice with fixed $w$,

$$
\begin{aligned}
& H(w)=0 \\
& H(s)=\log _{2} m \\
& T(s w)=0
\end{aligned}
$$

because $H(w)=0$.

For normal "ecological" situations, with $w \propto s$,

$$
\begin{gathered}
H(w)=-\sum_{i=1}^{n} p_{i} \cdot \log _{2} p_{i} \\
H(s)=-\sum_{k=1}^{m} p_{k} \cdot \log _{2} p_{k} \\
0 \leq T(s w) \leq \min [H(w), H(s)]
\end{gathered}
$$

and probably $T(s \psi w)<T(s w)$. Note that here $T(s w)$ is a variable, and if feedback is available, the organism can modify its environment to maximize $T(s w)$.

Maximum transmission in laboratory situations, with independent $s-r$ presentation probabilities, which are contrived and not natural quasi-random stimulus series, is

$$
\min \left[\log _{2} n, \log _{2} m\right]=\log _{2}[\min (n, m)] \text {. }
$$

It is of interest that Flournoy (1894) used a set of 10 common objects such as envelopes, a cigar box, and a penholder, all of exactly $112 \mathrm{~g}$ in weight, and had his subjects rank them in order of perceived lightness. The resultant $T(s \psi w)$ value was 1.58 , all objects being presented equally often to 49 observers, so that $H(w)=0, H(s)=3.23, T(s w)=0$.

It is suggested here that tuning cross-coupling by altering $\lambda$, in order to attempt to correct for $T(s w)$ being less than its potential maximum, is sufficient to produce the size-weight illusion.

\section{APPENDIX B: STATISTICS}

We note that hypothesis testing in the $2 \Gamma(\lambda, \eta)$ context is strongly model dependent. The only meaningful statistical in- 
ferences in this situation depend upon the use of Bayes prior probabilities.

In this approach, it is necessary first to distinguish useless from useful null hypotheses, by giving a prior probability to what is assumed in the light of previous experimental results (Press, 1989).

Useless null hypotheses are those with a prior probability of zero; in this context, the simplest null hypotheses are that perceived weights and perceived lengths are all equal because they are not discriminable. In our present notation these are ${ }_{0} H_{0}$,

$$
\begin{gathered}
{ }_{01} H_{0}: \operatorname{var}(\psi w \mid \phi w, \phi l)=0 \\
{ }_{02} H_{0}: \operatorname{var}(\psi l \mid \phi w, \phi l)=0 \\
\text { because } p\left({ }_{01} H_{0}\right) \rightarrow 0, \quad p\left({ }_{02} H_{0}\right) \rightarrow 0 .
\end{gathered}
$$

Given the previous body of data on size and weight perception, these are obviously false and can be discarded.

The next possibility is that there is linear additivity (ANOVA and Anderson's, 1967, information integration models are cases); the perceived weight is written as the sum of two stimulus properties:

$$
{ }_{1} H_{0}: \psi w=\alpha \phi w+\beta \phi l,
$$

or

$$
{ }_{1} H_{0}: \psi w=\alpha \phi w+(1-\alpha) \phi l .
$$

We have pointed out that these, although locally tenable, are known to be globally false, and can apparently hold only as approximations over a limited subset of $(\phi w, \phi l)$ values. Hence, $p\left({ }_{1} H_{0}\right) \rightarrow 0$.

The next null hypothesis to consider is entailed by the form of $2 \Gamma$, case 1 , namely for each dimension, and hence for each $\lambda$,

${ }_{2} H_{0}: \frac{\partial E}{\partial \lambda}=0 \mid .8 \leq \lambda \leq 1.3, \quad 2.8 \leq a_{1}, a_{2} \leq 4.2 \quad 2 \Gamma$.

This can be interpreted simply as saying that case 1 holds, but not case 2, which involves cross-coupling and partial compensation. The alternative is

$$
\begin{aligned}
{ }_{2} H_{1}: \exists \lambda^{*} \frac{\partial E}{\partial \lambda^{*}} & =0, \frac{\partial^{2} E}{\partial \lambda^{*^{2}}}>0, \\
\lambda^{*} \in \Lambda, \Lambda & =\{.8, \ldots, 1.3\},
\end{aligned}
$$

which means that there exists a local minimum (or best fit value) for some value of $\lambda$, in the range that yields reasonable univariate psychophysical mappings. In short, case 1 of $2 \Gamma$ can be taken as the $H_{0}$ for case 2 . The priors are now

$$
p\left({ }_{2} \mathrm{H}_{0}\right)=p\left({ }_{2} \mathrm{H}_{1}\right)=0.5 \text {. }
$$

This is most readily tested by rewriting the plot of

$$
\frac{\partial E}{\partial \lambda} \times \lambda
$$

in cumulative form, $C$, because now ${ }_{2} H_{0}$ implies that $C$ is a straight line parallel to the abscissa, whereas ${ }_{2} H_{1}$ implies that it is not, and departures from a straight line can be tested. Alternatively, for $N$ subjects, the distribution of departures from $H_{0}$ can be examined. It is only in this last sense that pooling data over subjects is legitimate.

Having found a minimum residual solution, the linear regression of scaled responses $\hat{Y}$ from

$$
\hat{Y}=\chi \cdot \psi w+\xi
$$

on fitted (minres) $Y$ should have a slope of 1 and an intercept of 0 . Compare Equation 12.

The posterior probability $p\left(2 \Gamma, \lambda_{1}, \lambda_{2} \mid E\right.$, data $)$ could be found by using Jeffreys's (1961) test on the associated correlation with $n^{\prime}=n-6 d f$.

(Manuscript received July 17, 1989; accepted for publication April 17, 1990.) 